\title{
Lagged Association Between Powdery Mildew Leaf Severity, Airborne Inoculum, Weather, and Crop Losses in Strawberry
}

\author{
O. Carisse, V. Morissette-Thomas, and H. Van der Heyden
}

First author: Agriculture and Agri-Food Canada, Horticulture Research and Development Centre, 430 Gouin Blvd., St. Jean-sur-Richelieu, QC, J3B 3E6, Canada; second author: Department of Mathematics, Sherbrooke University, Sherbrooke, QC, J1K 2R1, Canada; third author: Compagnie de recherche Phytodata Inc., 111 Rang St. Patrice, Sherrington, QC, JOL 2N0, Canada.

Accepted for publication 12 March 2013.

\begin{abstract}
Carisse, O., Morissette-Thomas, V., and Van der Heyden, H. 2013. Lagged association between powdery mildew leaf severity, airborne inoculum, weather, and crop losses in strawberry. Phytopathology 103:811-821.

Knowledge about epidemiology and the impact of disease on yield is fundamental for establishing effective management strategies. The purpose of this study was to investigate the relationship between foliar strawberry mildew severity, Podosphaera aphanis airborne inoculum concentration, weather, and subsequent crop losses for day-neutral strawberry. The experiment was conducted at three, five, and four sites in 2006, 2007, and 2008, respectively, for a total of 12 epidemics. At each site, data were collected on 25 plants at 2-day intervals from the end of May to early October for a total of 60 to 62 samplings annually. First, seasonal crop losses were statistically described; then, a lagged regression model was developed to describe crop losses from the parameters that were significantly associated with losses. There was a strong positive linear relationship between seasonal crop losses and the area under the leaf disease progress curve $\left(R^{2}=0.90\right)$ and daily mean airborne conidia concentration

time to $5 \%$ loss $\left(R^{2}=0.76\right)$ and time to $5 \%$ leaf area diseased $\left(R^{2}=0.61\right)$. Among the 53 monitoring- and weather-based variables analyzed, percent leaf area diseased, $\log _{10}$-transformed airborne inoculum concentration, and weather variables related to temperature were significantly associated with crop losses. However, polynomial distributed lag regression models built with weather variables were not accurate in predicting losses, with the exception of a model based on a combined temperature and humidity variable, which provided accurate prediction of the data used to construct the model but not of independent data. Overall, the model based on $\log _{10^{-}}$ transformed airborne inoculum concentration did not provide accurate crop loss predictions. The model built using percent leaf area diseased with a time lag of 8 days $(n=4)$ and a polynomial degree of 2 provided a good description of the crop-loss data used to construct the model $(r=$ 0.99 and 0.90$)$ and of independent data $(r=0.92)$. For the 12 epidemics studied, 5\% crop loss was reached when an average of $17 \%$ leaf area diseased was observed since the beginning of symptom development. These results indicate that information on foliar powdery mildew must be considered when making strawberry powdery mildew management decisions.
\end{abstract} $\left(R^{2}=0.86\right)$, and a negative linear relationship between crop losses and
A number of fruit diseases progress on foliage and on fruit as concomitant, lagged, or dual epidemics. For several such diseases, however, most of the knowledge on disease progress has been derived from analysis of data collected on foliage, with typical examples being apple scab (Venturia inaequalis), grape powdery mildew (Erisyphe necator), and grape downy mildew (Plasmopara viticola) $(6,13,24)$. Foliar disease severity seldom has been used for predicting fruit diseases (26). Strawberry powdery mildew caused by Podosphaera aphanis (Wallr.) U. Braun and S. Takam (formerly Sphaerotheca macularis f. fragariae (Harz) Jacz. can affect all aerial plant parts $(7,9,16)$. Although reduced photosynthesis induced by powdery mildew on leaves may cause a reduction in yield, most crop losses are attributable to flower and fruit infections $(7,9,16)$. Under severe epidemics, flowers are covered by mycelium and die before fruit setting (7). Pollen may also be contaminated, reducing pollen retention and resulting in poor fruit set $(12,16)$. Fruit infected when immature become hard and fail to ripen normally, while those infected at a later stage may dry out and have a shorter shelf life $(7,9,16)$. Despite the increasing prevalence of strawberry powdery mildew $(1,7,8,31$, $32)$, there is a scarcity of information on losses. Based on weekly assessments, incidences of fruit with powdery mildew of $\leq 25$ and

Corresponding author: O. Carisse; E-mail address: odile.carisse@agr.gc.ca

http://dx.doi.org/10.1094/PHYTO-11-12-0300-R

This article is in the public domain and not copyrightable. It may be freely reprinted with customary crediting of the source. The American Phytopathological Society, 2013
$85 \%$ were reported in the United States and Spain, respectively $(4,34)$.

In most instances, the objective of strawberry powdery mildew management programs is to control the disease on foliage in order to prevent damage to berries. Such management programs consist in applying fungicides at fixed intervals from blooming until the end of harvest; on June-bearing cultivars, fungicides are applied a few more times on regrowth foliage after renovation $(3,11)$. For quite a number of strawberry growers, scouting services exist, although it is difficult to improve fungicide spray schedules in absence of knowledge on yield or crop losses and, therefore, on action thresholds. This issue is especially acute during the harvest period for day-neutral strawberry cultivars (from mid-July to midOctober), because berries are harvested every 3 or 4 days. As a result, growers must time fungicide applications very carefully so that the preharvest interval expires before the next harvest.

The influence of weather conditions on several components of the disease cycle occurring on leaves is well documented $(1,14$, $19,22,23)$. Conidia germination has been reported to occur under a wide range of temperature and humidity conditions but was found in several studies to occur at temperatures of 15 to $25^{\circ} \mathrm{C}$ and relative humidity $(\mathrm{RH})$ levels $>75 \%(1,14,19,22)$. Conidia germination and colony development are inhibited by the presence of tissue wetness (i.e., free water) $(22,30)$. However, Miller et al. (19) reported that $\mathrm{RH}$, partial vapor pressure, and vapor pressure deficit were positively, positively, and negatively correlated, respectively, with the rate of lesion expansion. Incubation periods for leaf infections of 4 to 9 days have been reported (1,7,31). Pre- 
dicting strawberry powdery mildew is difficult because of this wide range of favorable weather conditions $(1,7,14,19,22,23$, $30,31)$. Among the few studies conducted on powdery mildew epidemics on berries, Blanco et al. (4) reported a positive correlation between weekly average aerial density of conidia and weekly average number of infected berries under field conditions in Spain. Recently, Carisse and Bouchard (7) reported that berry infection was more likely to occur 7 to 14 days after the occurrence of airborne conidia concentration (ACC) exceeding 500 conidia $\mathrm{m}^{-3} \mathrm{day}^{-1}$. In these studies, however, the lagged association between berry exposure to airborne inoculum and symptom expression was not considered. When the modeling objective is to predict crop losses, inclusion of the time lag association between independent variables and crop losses provides the model with an intrinsic predictive capability. One way to include the lag effect in regression models is to use polynomial distributed lag (PDL) regression (PDLREG) $(5,21,29)$. The purpose of this study was to investigate the influence of foliar disease severity, airborne inoculum concentration, and weather on subsequent crop losses. This was achieved first by statistically describing these relationships at the seasonal level and then by developing a lagged regression model for predicting crop losses from the parameters that significantly influenced losses.

\section{MATERIALS AND METHODS}

Experimental plots. The data were collected in three strawberry production areas in the province of Quebec, Canada: Frelighsburg (latitude $45^{\circ} 03^{\prime} 12^{\prime \prime} \mathrm{N}$; longitude $72^{\circ} 51^{\prime} 42^{\prime \prime} \mathrm{W}$ ), St. Paul-d'Abbotsford (latitude $45^{\circ} 25^{\prime} 60^{\prime \prime} \mathrm{N}$; longitude $72^{\circ} 52^{\prime} 60^{\prime \prime}$ W) and Ile d'Orléans (latitude $46^{\circ} 55^{\prime} 06^{\prime \prime} \mathrm{N}$; longitude $70^{\circ} 58^{\prime} 35^{\prime \prime}$ W). Data were collected in plots originally established to assess the effectiveness of various fungicides and timings on powdery mildew management. Here, only data collected in unsprayed (negative) control plots and in weekly sprayed (positive) control plots were used. The experiment was conducted at three, five, and four sites in 2006, 2007, and 2008, respectively, for a total of 12 epidemics. At all sites, day-neutral strawberry ('Seascape') was planted during spring (mid-May) in raised beds set $1.4 \mathrm{~m}$ apart and covered with black polyethylene mulch. Each bed had double rows, and the plants were spaced $30 \mathrm{~cm}$ apart within each row. Plots consisted of 13 raised beds measuring $15 \mathrm{~m}$ long at the Frelighsburg site, 15 raised beds measuring $30 \mathrm{~m}$ long at the St. Paul-d'Abbotsford site, and 13 raised beds measuring $12 \mathrm{~m}$ long at the Ile d'Orléans site. Flowers trusses were removed until midJune.

Data collection. Data were collected every 2 days from the last week of May to the first week of October for a total of 60 to 62 assessments per site-year. Data were collected on the same 25 plants in each plot, which had been randomly selected at the first sampling date. Foliar powdery mildew severity was assessed as the percent leaf area diseased (PLAD) on the three youngest fully expanded leaves using a diagrammatic scale with $5 \%$ steps $(0,5$, $10,15, \ldots, 100 \%)$. Airborne conidia concentration was monitored using two rotating-arm impaction spore samplers placed in the central row, at 5, 10, and $4 \mathrm{~m}$ upward and the other one at 5, 10, and $4 \mathrm{~m}$ downward from the middle of the plot at the Frelighsburg, St. Paul-d'Abbotsford, and Ile d'Orléans sites, respectively. The samplers ran for $20 \mathrm{~min}$ every hour $(10 \mathrm{~min}$ on and $20 \mathrm{~min}$ off) from 8:00 a.m. to 8:00 p.m. (4). After exposure, the number of conidia per rod was counted under a microscope at $\times 250$ magnification, and counts were transformed to number of conidia collected per cubic meter per day. $P$. aphanis conidia were identified based on their size ( 20 to 23 by 13 to $20 \mu \mathrm{m}$ ), their barrel shape when turgid, and the presence of granules inside the conidia (20). Daily ACC (conidia per cubic meter) (mean over the two samplers) were $\log$-transformed as $\log _{10}(\mathrm{ACC}+1)$. During the harvest periods, the total numbers of berries and of berries in- fected or discarded because of damage caused by $P$. aphanis were counted.

Weather data were obtained from an automatic weather station (CR-21X; Campbell Scientific Inc., Edmonton, AB, Canada) placed in an unobstructed area, $3 \mathrm{~m}$ from the plot edge. Weather data were monitored every $15 \mathrm{~min}$, and hourly averages or totals were used in the analyses. Temperature and RH probes were placed in a white shelter at $1.5 \mathrm{~m}$ above the ground. Rainfall was recorded with a tipping bucket rain gauge (Geneq, Montreal, QC, Canada) at a height of $50 \mathrm{~cm}$ above the ground. All weather variables were summarized over a day, a diurnal period, and a nocturnal period, which were defined as from 0:00 a.m. to 12:00 p.m., from 6:01 a.m. to 08:00 p.m., and from 08:01 p.m. to 6:00 a.m., respectively. Air temperature $\left({ }^{\circ} \mathrm{C}\right)$ and $\mathrm{RH}$ (percent) variables were expressed as averages, minima, and maxima. Rainfall was expressed as accumulated values (millimeters). For each period, the durations (hours) of temperature $\leq 15^{\circ} \mathrm{C}, \geq 20^{\circ} \mathrm{C}, \geq 25^{\circ} \mathrm{C}$, and between 15 and $25^{\circ} \mathrm{C}$; RH $\leq 55 \%, \leq 70 \%, \geq 90 \%$, between 75 and $85 \%$, and between 75 and $95 \%$; and rainfall $>2 \mathrm{~mm}$ were calculated. Finally, a variable characterizing a cold and humid night followed by a hot and dry day (CHN-HDD) was calculated as the daily number of hours of night temperature $\leq 15^{\circ} \mathrm{C}$ at $\mathrm{RH} \geq 90 \%$ and of day temperature $\geq 20$ at $\mathrm{RH} \leq 70 \%$. In total, 51 weather variables were used in the analysis.

Relationships between seasonal losses and epidemiological parameters. Strawberry attainable yield $\left(w_{0}\right)$ was expressed as the total number of marketable berries produced on the 25 plants sampled in the plots sprayed weekly (i.e., in absence or nearabsence of disease). Actual yield (w) (i.e., harvestable yield) was expressed as the total number of marketable fruit produced on the 25 sampled plants in the unsprayed plots. Seasonal crop loss $(l)$ was calculated as $l=\left(w_{0}-\mathrm{w}\right) / w_{0}$. Linear regression was used to analyze the relationships between various parameters characterizing epidemics and seasonal crop losses for the 12 epidemics, as $l=\beta_{0}+\beta_{1} x$, where $l$ is the relative crop loss, $\beta_{0}$ and $\beta_{1}$ are regression parameters, and $x$ is a parameter describing epidemics. The following parameters were analyzed: the area under the leaf disease progress curve (AUDPC) standardized for the duration of the epidemic, mean daily conidia concentration (ACC), time to $5 \%$ leaf area diseased, and time to 5\% crop loss. The regression analysis was conducted using PROC REG in the SAS software program (version 9.2; SAS Institute Inc., Cary, NC).

Modeling the dynamics of crop losses using lagged regression analysis. For each assessment date, crop loss increment $\left(l_{t}\right)$ was calculated as the number of berries discarded owing to $P$. aphanis in the unsprayed plots divided by the attainable production $\left(w_{0}\right)$ for the given epidemic multiplied by 100 . To model the temporal dynamics of seasonal crop losses due to strawberry powdery mildew $\left(l_{t}\right)$, our hypothesis was that crop loss on any given day $\left(l_{t}\right)$ was related to the severity of powdery mildew on foliage, airborne inoculum concentration, and a number of weather variables occurring some days earlier. Therefore, the temporal dynamic of strawberry crop losses was modeled as a function of these variables using distributed lag regression and general linear model analysis $(21,25,28)$. The distributed lag regression model was developed with data from 9 epidemics selected randomly out of the 12 epidemics and tested against the data from the remaining 3 epidemics. These analyses were conducted using PDLREG in the SAS software program (version 9.2; SAS Institute Inc.).

PDLREG analysis was described in detail by Paul et al. (21). In brief, PDLREG can be used to estimate regression models for time series data in which the effects of some of the independent variables $\left(X\right.$; in this study: PLAD, $\log _{10}[\mathrm{ACC}+1]$, and weather variables) are distributed over time. In distributed lag modeling, it is assumed that the dependent variable $\left(Y\right.$; in this study: $\left.l_{t}\right)$ form a time series and that the effect of $X$ on $Y$ is distributed over time. In other words, if the value of $X$ at time $t$ changes, it will influence the value of $Y$ at time $t$ and at time $t+1, t+2, t+3$, up to $t+n$. 
The PDLREG model can handle a large number of independent variables $(X)$ and covariates (variables without lag distributions). Thus, the general form of the PDLREG model when only one independent variable is considered, as follows:

$$
Y_{t}=\alpha+\sum_{i=0}^{n} \beta_{i} X_{t-i}+\gamma z_{t}+e_{t}
$$

where $Y_{t}$ is the dependent or response variable (here: $l_{t}$ ), $n$ is the lag duration, $\alpha$ is the intercept parameter (which is the expected value of $Y$ when all $X$ and $\mathrm{z}$ are 0$), \beta_{i}$ is a parameter corresponding to $X_{t}, X_{t}$ is the independent variable with distributed lag effect, $z_{t}$ is a covariate, $\gamma$ is a parameter corresponding to $z_{t}$, and $e_{t}$ is an error term. In the present case, however, no covariates such as year or location of sampling were considered in the analysis. Thus, equation 1 can be rewritten as follows:

$$
Y_{t}=\alpha+\sum_{i=0}^{n} \beta_{i} X_{t-i}+e_{t}
$$

The distribution of the lagged effects of $X$ on $Y$ was modeled by lag polynomials, and the coefficients $\left(\beta_{i}\right)$ of the lagged values of $X$ were assumed to follow a polynomial curve (equation 3 ). In the PDLREG procedure, orthogonal polynomials are used for estimation, and $\beta_{i}$ can be calculated as follows:

$$
\beta_{i}=\alpha_{0}+\sum_{j=1}^{d} \alpha_{j} f_{j}(i)
$$

where $\alpha_{0}$ is the intercept parameter, $d(\leq n)$ is the degree of the polynomial, $\alpha_{j}$ is the estimated coefficients determined from the data, and $f_{j}(i)$ is a polynomial of degree $j$ in the lag duration $i$.

PDLREG model fitting. PDLREG models with unconstrained parameters were constructed using PROC PDLREG of SAS in two steps. The first step consisted of establishing the time lag duration $(n)$ over which the independent variables $(X)$ influenced losses $(Y)$. The time lag duration $(n)$ was established for each of the 51 weather variables, $\log _{10}(\mathrm{ACC}+1)$, and PLAD by fitting equation 2 to each variable for lag durations $(n)$ of 0 to 7 , which corresponded to 0 to 14 days. These lag durations were chosen based on recent work by Sombardier et al. (31), who reported latent periods of $\leq 7$ days, and by Carisse and Bouchard (7), who observed symptoms of powdery mildew on berries 14 days after inoculation. Models were assessed based on the mean square error (MSE) and Akaike information criterion for parsimony (AIC) (28). The second step consisted of determining the polynomial degree (d) individually for each of the variables with the lag duration that was selected from the first step of the PDL analysis (equation 3). This was done using the method incorporated into the PDLREG procedure based on orthogonal polynomials which was described in detailed by Paul et al. (21). A polynomial term was considered significant and, therefore, was retained if the absolute value of its associated Student's $t$ statistic was greater than 1.5 (21).

Model analysis and testing. Because of the presence of serial correlations of the residuals, and to facilitate the inclusion of several independent variables in the model, composite variables were built $\left(X^{*}\right)$ for each of the independent variables that best explained the variability of $Y$ and were selected in the PDLREG modeling (variables for which the MSE and AIC values were low). Because only linear models were considered in the PDL analysis and no covariates were included in the model, the distributed lag model (equation 1) can be written as follows:

$$
Y=\alpha+\beta_{0} X_{t}+\beta_{1} X_{t-1}+\beta_{2} X_{t-2}+\ldots \beta_{n} X_{t-n}+e_{t}
$$

If we consider $m$ to be the time lag $(m=0, \ldots, n), \beta_{m}$ could be used to represent an individual $\beta$ at a specific lag, as $\Sigma \beta_{m}=\beta^{*}=$ $\beta_{0}+\beta_{1}+\ldots+\beta_{n}$. The relative importance or weight ( $\left.w\right)$ of $X$ on each day in terms of predicting $Y$ could be calculated as $w_{m}=$ $\beta_{m} / \beta^{*}$, where $w_{1}=\beta_{1} / \beta^{*}, w_{2}=\beta_{2} / \beta^{*}, \ldots, w_{m}=\beta_{m} / \beta^{*}$. The sum of the $w$ values is equal to 1 , and $\beta^{*}$ corresponds to the change in $Y$ with a unit change in $X$. Thus, equation 4 can be written as follows:

$$
Y_{t}=\alpha+\beta^{*}\left(w_{0} X_{t}+w_{1} X_{t-1}+w_{2} X_{t-2}+\ldots w_{n} X_{t-n}\right)+e_{t}
$$

or

$$
Y_{t}=\alpha+\beta^{*} X^{*}+e_{t}
$$

The weights $\left(w_{m}\right)$ were calculated from the $\beta_{m}$ values, based on the selected $n$ and $d$ from the PDLREG analysis, and the composite variables were defined as follows:

$$
X_{i, t}^{*}=w_{0} X_{i, t}+w_{1} X_{i, t-1}+w_{2} X_{i, t-2} \ldots+w_{n} X_{i, t-n}
$$

Linear models were then used to model the dynamics of crop losses $\left(Y_{t}\right)$ as a function of various selected variables, as follows:

$$
Y_{t}=\alpha+\beta_{1}^{*} X_{1}^{*}+\beta_{2}^{*} X_{2}^{*}+\beta_{3}^{*} X_{3}^{*}+e_{t}
$$

where $\hat{Y}$ is the predicted crop losses; $X^{*}{ }_{1}, X^{*}{ }_{2}$, and $X^{*}{ }_{3}$ are composite variables; and $e$ is the residual. All terms in the model are fixed effects, with the exception of $e$, which is a random effect. First, 9 models, each one containing one of the selected variables, and 4 additional models including combinations of monitoringbased (PLAD or $\log _{10}[\mathrm{ACC}+1]$ ) and the variable CHN-HDD, for a total of 13 models, were fitted to the pooled data using PROC GLIMMIX of SAS with the restricted maximum likelihood method. Second, the best models $(r>0.85)$ were tested against the nine data sets used to construct the models and against the three data sets that were not used to construct the models. These models were evaluated by performing a simple regression analysis between the predicted values and the corresponding observations as paired data (goodness of fit between predicted and observed values) (10). To further evaluate the six models, the concordance correlation coefficient (CCC) was used as a measure of accuracy (17). The CCC was calculated as $r \times C_{b}$, where $r$ is the Pearson product-moment correlation between observed and predicted crop losses and $C_{b}$ is a bias coefficient. The bias coefficient is the deviation of the best-fitting line from the concordance line (perfect agreement between observed and predicted crop losses), which is a straight line with an intercept of 0 and a slope of 1 (17).

\section{RESULTS}

For the 3 years and the three production areas, the harvest started between 4 July (day 186) and 19 July (day 201) and ended between 8 September (day 252) and 24 September (day 268) (Fig. 1). During that period, current crop losses were 0.00 to $3.50 \%$ (Fig. 1) and the relative crop losses were 9.04 to $29.8 \%$ (Fig. 2). For most epidemics, the progress of powdery mildew on leaves (PLAD) followed a temporal pattern similar to that of the progress of crop losses but occurred a few days earlier (Fig. 1). The mean PLAD was 6.94 to $17.93 \%$ (Fig. 2). The temporal pattern of ACC followed a bell-shaped curve with low concentrations early in the season, an increase in ACC to a peak in mid-season, and decreasing ACC toward the end of the season (Fig. 1).

Relationships between seasonal losses and epidemiological parameters. At the seasonal level, there was a linear relationship 
between crop losses and seasonal variation in ACC, AUDPC, time to first observation of PLAD $\geq 5 \%$, and time to $5 \%$ crop loss (Fig. 2A to D). The parameters that best described the seasonal crop losses were the AUDPC and ACC, with $R^{2}$ of 0.90 and 0.86 , respectively (Fig. 2A and B). The time to first observation of PLAD $\geq 5 \%$ explained a large fraction of the seasonal crop losses variation $\left(R^{2}=0.76\right)$, whereas time to $5 \%$ crop loss accounted for only $61 \%$ of the variation in seasonal crop losses (Fig. 2C and D).

PDLREG model fitting: determination of lag duration and polynomial degree. The best time lag was chosen based on the fit of equation 2 to each of the 51 weather-based variables and the two monitoring-based variables (PLAD and $\log _{10}$-transformed ACC) for lag durations of 0 to 7 (i.e., 0 to 14 days) (Table 1). For the weather-based variables, in general, there were only small variations in both the MSE and AIC values, which decreased with increasing lag to reach a minimum at approximately a lag of 6 or 7, corresponding to 12 to 14 days. An exception was the variable CHN-HDD, for which the lowest MSE and AIC values were for a lag of 4 (8 days). The lowest MSE value for CHN-HDD was 0.11 for lag of 4 (Table 1). Similar to the weather-based variables, for the $\log _{10}$-transformed ACC, the variation in the MSE and AIC values over the time lag was small but lowest at a lag of 3 (Table 1). The MSE value for log-transformed ACC was 0.26, except for lag 0, for which it was 0.27 (Table 1). For the PLAD variable, both the MSE and AIC values decreased from a lag of 0 to a lag of 3 and remained low thereafter (Table 1). The MSE values for PLAD at lags of 0,1 , and 2 were $0.35,0.19$, and 0.26 , respec-
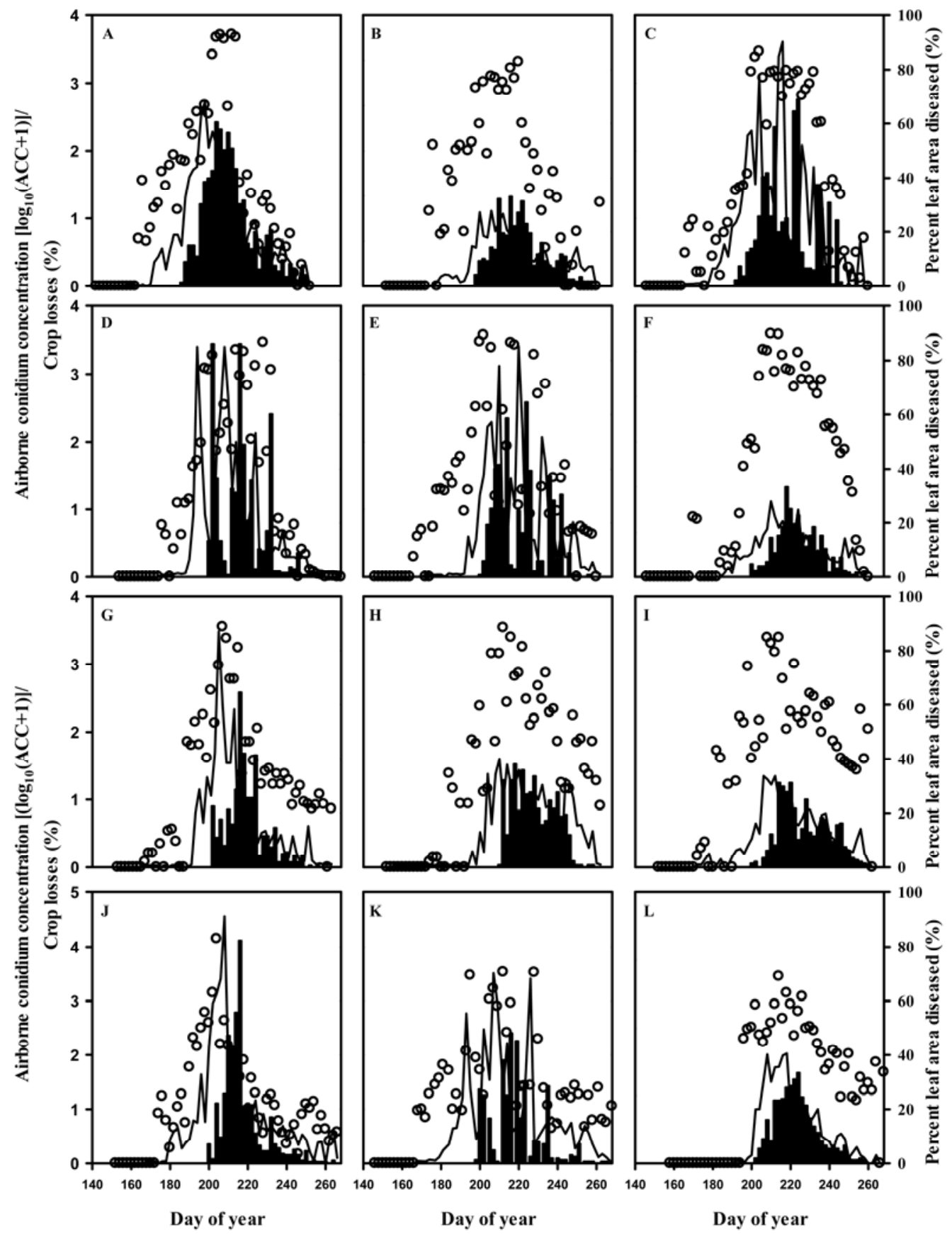

Fig. 1. Temporal progress of strawberry crop losses (bars) caused by Podosphaera aphanis, percent leaf area diseased (line), and log-transformed airborne conidia concentration $\left(\log _{10}[\mathrm{ACC}+1]\right)(\mathrm{dots})$ in 12 strawberry fields in 2006, 2007, and 2008 in Quebec, Canada. A to I, Data were used for model development as follows: A and B, collected in 2006 at the Ile d'Orléans and Frelighsburg sites, respectively; C to F, collected in 2007 at d'Orléans, Ile d'Orléans, St. Pauld'Abbotsford, and Frelighsburg sites, respectively; and $\mathbf{G}$ to I, collected in 2008 at the St. Paul-d'Abbotsford site. J to L, Data were used for model testing as follows: J to L, collected in 2006, 2007, and 2007 at the Ile d'Orléans, St. Paul-d'Abbotsford, and Frelighsburg sites, respectively. 
tively, and dropped to 0.06 at lags of 3 to 7 (Table 1). Based on both the MSE and AIC, the variables that had the greatest influence (smaller MSE and AIC values) on crop losses $(Y)$ were PLAD, $\log (\mathrm{ACC}+1)$, number of hours with temperature $\geq 25^{\circ} \mathrm{C}$ (T25), mean temperature (T), minimum temperature (MinT), number of hours during the night with temperature $\leq 15^{\circ} \mathrm{C}$ (NT15), minimum day temperature (DMinT), minimum night temperature (NMinT), and daily number of hours of night temperature $\leq 15^{\circ} \mathrm{C}$ at $\mathrm{RH} \geq 90 \%$ and day temperature $\geq 20^{\circ} \mathrm{C}$ at $\mathrm{RH} \leq 70 \%$ (CHNHDD). These variables were selected for model development and the appropriate time lag was selected based on the smallest MSE and AIC values for all the time lags tested ( 0 to 7 ). Time lags of 4 , $3,7,7,7,7,7,7$, and 4 were selected for the variables PLAD, $\log _{10}(\mathrm{ACC}+1)$, T25, T, MinT, NT15, DMinT, NMinT, and CHNHDD, respectively (Table 1). For PLAD, $\log _{10}(\mathrm{ACC}+1)$, T25, T, MinT, NT15, DMinT, NMinT, and CHN-HDD, the selected polynomial degrees were $2,1,2,1,1,2,1,1$, and 1 , respectively (Table 2).

Model evaluation and testing. The final step in modeling the effect of the monitoring- and weather-based variables on crop losses consisted of fitting linear models (equation 8) containing one to three of the nine selected variables expressed as composite variables (Table 3). In total, 13 models were evaluated (Table 3). When these models were fitted to the pooled data used to con- struct the composite variables (Fig. 1A to I), the best fits were obtained for the models containing PLAD as the predictor variable. For instance, models containing PLAD (M1), PLAD + $\log _{10}(\mathrm{ACC}+1)(\mathrm{M} 10)$, PLAD + CHN-HDD (M11), and PLAD + $\log _{10}(\mathrm{ACC}+1)+\mathrm{CHN}-\mathrm{HDD}(\mathrm{M} 13)$ had coefficients of correlation $(r)$ between observed and predicted values of $0.99,0.99$, 0.98 , and 0.99 , respectively (Table 3 ). The model with $\log _{10}(\mathrm{ACC}+$ 1 ) as the sole predictor variable (M2) had an $r$ value of 0.88 , which was improved to 0.91 when CHN-HDD was added (M12) and to 0.99 when both PLAD and CHN-HDD were added (M13). Overall, models containing one weather-based variable had lower correlation coefficients of 0.40 to 0.73 , with the exception of the model containing CHN-HDD (M9), with 0.89 (Table 3). Based on these results, seven models were selected-PLAD (M1), $\log (\mathrm{ACC}$ + 1) (M2), CHN-HDD (M9), PLAD + $\log _{10}(\mathrm{ACC}+1)(\mathrm{M} 10)$, PLAD + CHN-HDD (M11), $\log (\mathrm{ACC}+1)+\mathrm{CHN}-\mathrm{HDD}(\mathrm{M} 12)$, and PLAD $+\log (\mathrm{ACC}+1)+\mathrm{CHN}-\mathrm{HDD}(\mathrm{M} 13)$ - and fitted to each of the nine data sets used to construct the PDLREG models (Fig. 1A to I). The correlation coefficient was 0.60 to 0.90 , with the coefficient of bias at 0.70 to 0.96 and $\mathrm{CCC}$ at 0.43 to 0.86 (Figs. 3A and $\mathrm{B}$ and $4 \mathrm{~A}$ to $\mathrm{E}$ ). For the six models, no pattern could be detected in the residuals.

When these models were fitted to the three data sets not used to construct the PDL models (Fig. 1J and K), the correlation coef-
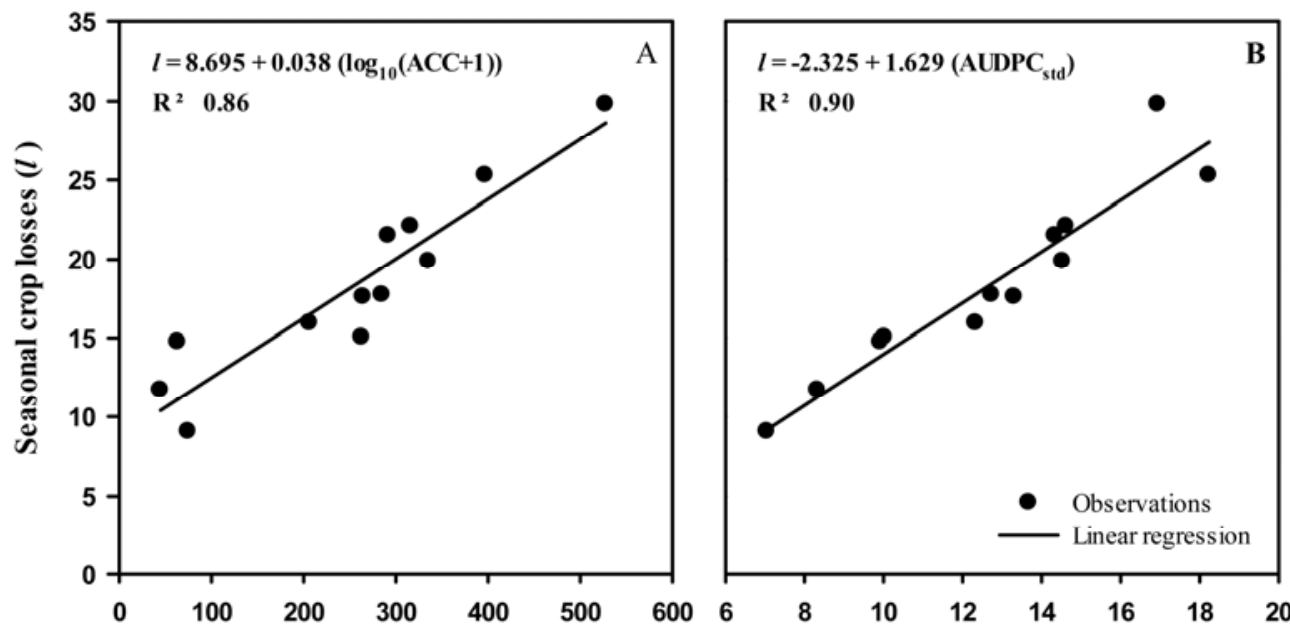

Airborne conidium concentration $\left(\log _{10}(\mathbf{A C C}+1)\right)$

Area under the diseased progress curve (AUDPC std )

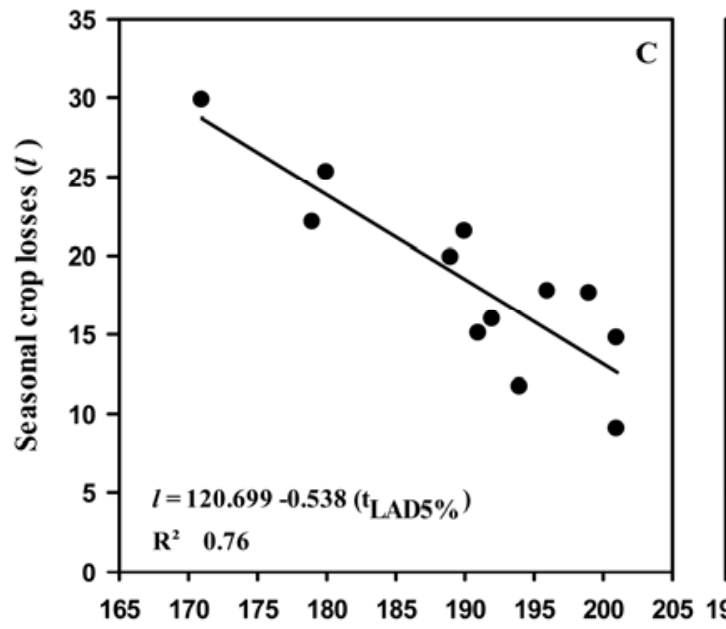

Time to $5 \%$ leaf area diseased $\left(t_{\text {LAD5\% }}\right)$

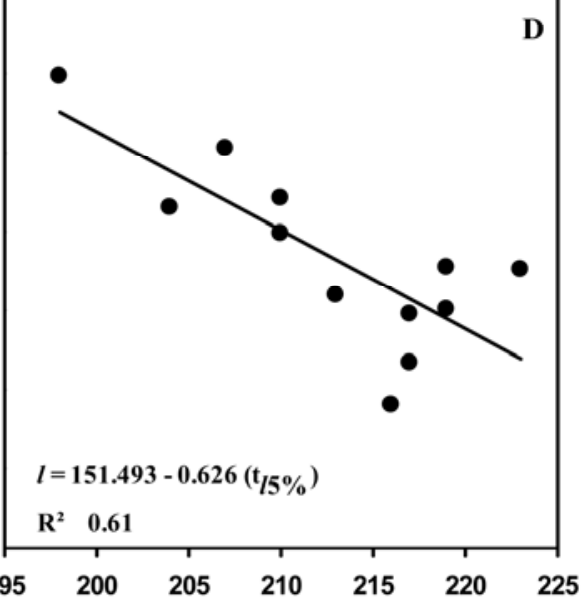

Time to $5 \%$ crop losses $\left(\mathrm{t}_{15 \%}\right)$

Fig. 2. Relationships between strawberry seasonal crop losses caused by Podosphaera aphanis and variables characterizing epidemics. Data were collected in 12 strawberry fields in 2006, 2007, and 2008 in Quebec, Canada. ACC $=$ airborne conidia concentration and AUDPC $_{\text {std }}=$ area under the leaf disease progress curve standardized for the duration of the epidemic. 


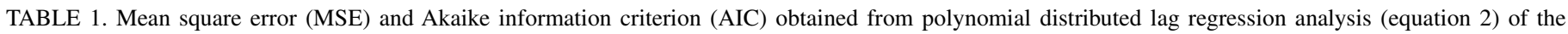
relationship between monitoring- and weather-based variables and percent yield losses for temporal lag durations of 0 to 7

\begin{tabular}{|c|c|c|c|c|c|c|c|c|c|}
\hline \multirow[b]{2}{*}{ Variables $^{\mathrm{a}}$} & \multirow[b]{2}{*}{ Statistics } & \multicolumn{8}{|c|}{ Lag duration $^{\mathrm{b}}$} \\
\hline & & 0 & 1 & 2 & 3 & 4 & 5 & 6 & 7 \\
\hline \multirow[t]{2}{*}{ LACC } & MSE & 0.27 & 0.26 & 0.26 & 0.26 & 0.26 & 0.26 & 0.26 & 0.26 \\
\hline & $\mathrm{AIC}$ & 478.17 & 468.43 & 467.87 & 467.57 & 469.57 & 471.28 & 472.90 & 474.69 \\
\hline \multirow[t]{2}{*}{ PLAD } & MSE & 0.35 & 0.19 & 0.26 & 0.06 & 0.06 & 0.06 & 0.06 & 0.06 \\
\hline & $\mathrm{AIC}$ & 559.57 & 534.92 & 468.78 & 34.68 & 22.38 & 24.01 & 24.91 & 26.28 \\
\hline \multirow[t]{2}{*}{ HRH90 } & MSE & 0.41 & 0.41 & 0.41 & 0.41 & 0.41 & 0.41 & 0.41 & 0.41 \\
\hline & $\mathrm{AIC}$ & 612.93 & 614.93 & 616.75 & 615.19 & 616.36 & 618.30 & 620.16 & 622.07 \\
\hline \multirow[t]{2}{*}{ HRH75-95 } & MSE & 0.41 & 0.41 & 0.41 & 0.41 & 0.41 & 0.41 & 0.41 & 0.41 \\
\hline & $\mathrm{AIC}$ & 612.15 & 613.57 & 615.38 & 614.90 & 613.60 & 615.40 & 617.17 & 616.71 \\
\hline \multirow{2}{*}{ HRH75-85 } & MSE & 0.41 & 0.41 & 0.41 & 0.41 & 0.42 & 0.42 & 0.42 & 0.42 \\
\hline & AIC & 613.36 & 615.00 & 616.85 & 618.73 & 620.73 & 622.72 & 624.47 & 624.74 \\
\hline \multirow[t]{2}{*}{ HRH-70 } & MSE & 0.41 & 0.41 & 0.41 & 0.41 & 0.40 & 0.40 & 0.40 & 0.40 \\
\hline & AIC & 612.98 & 614.18 & 616.18 & 612.64 & 610.38 & 611.82 & 611.23 & 608.66 \\
\hline \multirow{2}{*}{ HRH55 } & MSE & 0.41 & 0.41 & 0.41 & 0.41 & 0.41 & 0.40 & 0.40 & 0.39 \\
\hline & AIC & 612.16 & 613.97 & 615.97 & 614.92 & 612.87 & 611.87 & 609.55 & 607.23 \\
\hline \multirow[t]{2}{*}{ HT25 } & MSE & 0.36 & 0.36 & 0.36 & 0.35 & 0.34 & 0.34 & 0.34 & 0.33 \\
\hline & AIC & 571.59 & 571.08 & 570.41 & 566.16 & 560.42 & 555.24 & 555.02 & 551.30 \\
\hline HT15-25 & MSE & 0.39 & 0.38 & 0.38 & 0.39 & 0.39 & 0.39 & 0.39 & 0.39 \\
\hline & $\mathrm{AIC}$ & 596.13 & 593.41 & 594.14 & 595.77 & 597.70 & 598.87 & 600.05 & 601.90 \\
\hline HT15 & MSE & 0.40 & 0.40 & 0.41 & 0.41 & 0.41 & 0.41 & 0.41 & 0.41 \\
\hline & $\mathrm{AIC}$ & 607.64 & 609.16 & 611.07 & 612.96 & 614.49 & 616.47 & 617.35 & 619.34 \\
\hline $\mathrm{T}$ & MSE & 0.36 & 0.35 & 0.35 & 0.35 & 0.35 & 0.35 & 0.35 & 0.35 \\
\hline & AIC & 569.87 & 567.79 & 568.93 & 569.21 & 567.76 & 566.15 & 566.90 & 567.33 \\
\hline MinT & MSE & 0.36 & 0.36 & 0.36 & 0.35 & 0.35 & 0.34 & 0.33 & 0.33 \\
\hline & AIC & 575.51 & 572.30 & 573.16 & 566.07 & 562.08 & 556.77 & 553.29 & 550.75 \\
\hline MaxT & MSE & 0.38 & 0.37 & 0.37 & 0.38 & 0.38 & 0.38 & 0.38 & 0.38 \\
\hline & $\mathrm{AIC}$ & 584.97 & 584.26 & 585.95 & 587.84 & 589.35 & 590.84 & 592.71 & 594.49 \\
\hline RH & MSE & 0.41 & 0.41 & 0.41 & 0.41 & 0.41 & 0.41 & 0.41 & 0.40 \\
\hline & AIC & 611.08 & 613.07 & 614.86 & 612.11 & 612.60 & 614.58 & 615.28 & 614.68 \\
\hline MinRH & MSE & 0.41 & 0.41 & 0.41 & 0.41 & 0.40 & 0.40 & 0.40 & 0.40 \\
\hline & AIC & 609.92 & 611.59 & 612.40 & 611.29 & 611.66 & 612.86 & 612.96 & 609.88 \\
\hline MaxRH & MSE & 0.41 & 0.41 & 0.41 & 0.41 & 0.41 & 0.41 & 0.41 & 0.41 \\
\hline & $\mathrm{AIC}$ & 612.52 & 614.48 & 615.40 & 616.07 & 618.07 & 618.57 & 620.49 & 621.88 \\
\hline RAIN & MSE & 0.38 & 0.41 & 0.41 & 0.41 & 0.41 & 0.41 & 0.41 & 0.41 \\
\hline & AIC & 584.97 & 615.35 & 617.00 & 617.52 & 618.72 & 620.04 & 620.30 & 621.89 \\
\hline HRAIN & MSE & 0.41 & 0.41 & 0.41 & 0.41 & 0.41 & 0.41 & 0.39 & 0.39 \\
\hline & AIC & 612.83 & 614.46 & 616.44 & 617.48 & 615.64 & 613.60 & 604.80 & 602.07 \\
\hline DRH90 & MSE & 0.41 & 0.41 & 0.41 & 0.41 & 0.41 & 0.41 & 0.41 & 0.41 \\
\hline & $\mathrm{AIC}$ & 612.24 & 614.23 & 616.22 & 615.62 & 617.28 & 618.80 & 620.23 & 622.11 \\
\hline HDRH75-95 & MSE & 0.41 & 0.41 & 0.41 & 0.41 & 0.40 & 0.41 & 0.41 & 0.41 \\
\hline & $\mathrm{AIC}$ & 612.46 & 614.25 & 616.24 & 612.59 & 612.07 & 614.04 & 615.92 & 616.29 \\
\hline HDRH75-85 & MSE & 0.38 & 0.41 & 0.41 & 0.41 & 0.40 & 0.41 & 0.41 & 0.41 \\
\hline & $\mathrm{AIC}$ & 584.97 & 614.25 & 616.24 & 612.59 & 612.07 & 614.04 & 615.92 & 616.29 \\
\hline HDRH-70 & MSE & 0.41 & 0.41 & 0.41 & 0.41 & 0.40 & 0.40 & 0.40 & 0.40 \\
\hline & $\mathrm{AIC}$ & 612.67 & 614.02 & 616.00 & 611.64 & 611.40 & 611.80 & 611.87 & 611.14 \\
\hline HDRH55 & MSE & 0.41 & 0.41 & 0.41 & 0.41 & 0.41 & 0.41 & 0.41 & 0.40 \\
\hline & AIC & 612.35 & 614.32 & 616.05 & 615.36 & 615.66 & 615.92 & 614.63 & 614.32 \\
\hline HDT25 & MSE & 0.39 & 0.39 & 0.38 & 0.38 & 0.39 & 0.39 & 0.40 & 0.39 \\
\hline & AIC & 599.35 & 593.66 & 593.71 & 594.96 & 596.51 & 597.70 & 599.25 & 600.96 \\
\hline HDT15-25 & MSE & 0.41 & 0.41 & 0.41 & 0.41 & 0.41 & 0.41 & 0.41 & 0.42 \\
\hline & $\mathrm{AIC}$ & 611.92 & 613.21 & 614.98 & 616.56 & 617.90 & 619.86 & 621.61 & 623.41 \\
\hline HDT15 & MSE & 0.37 & 0.37 & 0.37 & 0.36 & 0.35 & 0.34 & 0.34 & 0.33 \\
\hline & AIC & 581.47 & 578.55 & 577.88 & 573.88 & 565.76 & 560.20 & 557.69 & 554.92 \\
\hline DT & MSE & 0.38 & 0.36 & 0.36 & 0.36 & 0.35 & 0.35 & 0.35 & 0.35 \\
\hline & AIC & 584.97 & 568.86 & 569.65 & 571.05 & 569.31 & 568.93 & 569.98 & 571.09 \\
\hline DMinT & MSE & 0.36 & 0.35 & 0.35 & 0.34 & 0.34 & 0.33 & 0.33 & 0.33 \\
\hline & AIC & 572.40 & 567.19 & 567.55 & 560.80 & 555.56 & 548.45 & 547.43 & 547.99 \\
\hline DMaxT & MSE & 0.38 & 0.38 & 0.38 & 0.38 & 0.38 & 0.38 & 0.38 & 0.38 \\
\hline & AIC & 587.12 & 585.22 & 587.04 & 588.90 & 590.23 & 592.02 & 594.00 & 596.00 \\
\hline DRH & MSE & 0.41 & 0.41 & 0.41 & 0.40 & 0.41 & 0.41 & 0.41 & 0.40 \\
\hline & AIC & 609.93 & 611.93 & 613.44 & 611.00 & 612.33 & 614.07 & 614.84 & 615.02 \\
\hline DMinRH & MSE & 0.41 & 0.41 & 0.41 & 0.40 & 0.40 & 0.40 & 0.40 & 0.40 \\
\hline & AIC & 609.03 & 611.03 & 612.44 & 608.28 & 607.92 & 608.76 & 609.21 & 607.58 \\
\hline DMaxRH & MSE & 0.41 & 0.41 & 0.41 & 0.41 & 0.41 & 0.41 & 0.41 & 0.41 \\
\hline & AIC & 610.02 & 611.89 & 613.87 & 615.24 & 615.79 & 617.16 & 618.54 & 619.67 \\
\hline
\end{tabular}

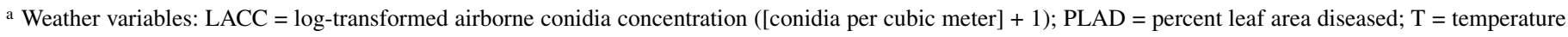
$\left({ }^{\circ} \mathrm{C}\right) ; \mathrm{RH}=$ relative humidity (percent); RAIN = rain (millimeters); CHN-HDD = a cold and humid night followed by a hot and dry day; and Min, Max, D, N, and $\mathrm{H}=$ minimum, maximum, daytime, nighttime, and number of hours, respectively.

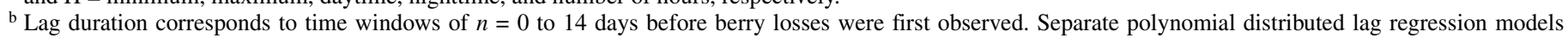
(with no constraint on the polynomial degree [i.e., $d=n$ ]) were fitted to each weather variable for each lag duration using 386 observations collected in 2006 , 2007, and 2008 at six strawberry fields (Fig. 1A to I). Both MSE and AIC adjust for the number of parameters in the model and, in both cases, the smaller the statistic, the better the fit. 


\begin{tabular}{|c|c|c|c|c|c|c|c|c|c|}
\hline \multirow[b]{2}{*}{ Variables $^{\mathrm{a}}$} & \multirow[b]{2}{*}{ Statistics } & \multicolumn{8}{|c|}{ Lag duration ${ }^{\mathrm{b}}$} \\
\hline & & 0 & 1 & 2 & 3 & 4 & 5 & 6 & 7 \\
\hline \multirow[t]{2}{*}{ DRAIN } & MSE & 0.41 & 0.41 & 0.41 & 0.41 & 0.41 & 0.41 & 0.41 & 0.42 \\
\hline & $\mathrm{AIC}$ & 612.88 & 614.34 & 615.77 & 615.61 & 617.52 & 619.50 & 621.10 & 622.87 \\
\hline \multirow[t]{2}{*}{ DRAIND } & MSE & 0.41 & 0.41 & 0.41 & 0.41 & 0.41 & 0.41 & 0.41 & 0.41 \\
\hline & $\mathrm{AIC}$ & 612.73 & 613.42 & 615.41 & 617.00 & 618.66 & 619.89 & 618.10 & 619.77 \\
\hline \multirow[t]{2}{*}{ HNRH90 } & MSE & 0.41 & 0.41 & 0.41 & 0.41 & 0.41 & 0.41 & 0.41 & 0.42 \\
\hline & $\mathrm{AIC}$ & 612.53 & 614.24 & 615.94 & 616.42 & 618.18 & 620.10 & 621.76 & 623.59 \\
\hline \multirow[t]{2}{*}{ HNRH75-95 } & MSE & 0.41 & 0.41 & 0.41 & 0.41 & 0.41 & 0.42 & 0.42 & 0.42 \\
\hline & AIC & 612.34 & 614.21 & 616.01 & 617.73 & 619.54 & 620.90 & 622.82 & 624.50 \\
\hline \multirow[t]{2}{*}{ HNRH75-85 } & MSE & 0.41 & 0.41 & 0.41 & 0.41 & 0.41 & 0.41 & 0.41 & 0.41 \\
\hline & $\mathrm{AIC}$ & 610.36 & 611.73 & 612.67 & 612.35 & 613.45 & 615.34 & 617.29 & 619.28 \\
\hline \multirow[t]{2}{*}{ HNRH-70 } & MSE & 0.41 & 0.41 & 0.41 & 0.41 & 0.41 & 0.41 & 0.41 & 0.41 \\
\hline & $\mathrm{AIC}$ & 612.75 & 613.33 & 615.30 & 614.39 & 614.03 & 615.92 & 616.93 & 618.26 \\
\hline \multirow[t]{2}{*}{ HNRH55 } & MSE & 0.41 & 0.41 & 0.41 & 0.40 & 0.40 & 0.40 & 0.40 & 0.40 \\
\hline & AIC & 610.95 & 611.60 & 611.80 & 611.80 & 611.96 & 612.37 & 613.32 & 614.72 \\
\hline \multirow[t]{2}{*}{ HNT25 } & MSE & 0.41 & 0.41 & 0.40 & 0.40 & 0.40 & 0.40 & 0.40 & 0.40 \\
\hline & AIC & 609.52 & 609.77 & 609.64 & 609.52 & 611.10 & 612.31 & 613.63 & 613.98 \\
\hline \multirow[t]{2}{*}{ HNT15-25 } & MSE & 0.39 & 0.39 & 0.39 & 0.39 & 0.39 & 0.39 & 0.40 & 0.40 \\
\hline & AIC & 597.89 & 599.54 & 601.54 & 602.02 & 603.69 & 605.28 & 607.06 & 609.04 \\
\hline \multirow[t]{2}{*}{ HNT15 } & MSE & 0.37 & 0.37 & 0.36 & 0.37 & 0.35 & 0.35 & 0.35 & 0.34 \\
\hline & $\mathrm{AIC}$ & 581.29 & 577.73 & 577.45 & 571.60 & 568.30 & 564.07 & 564.30 & 563.28 \\
\hline \multirow[t]{2}{*}{ NT } & MSE & 0.37 & 0.36 & 0.36 & 0.36 & 0.36 & 0.36 & 0.35 & 0.35 \\
\hline & AIC & 563.28 & 576.57 & 577.74 & 574.94 & 574.06 & 572.04 & 572.51 & 572.90 \\
\hline \multirow[t]{2}{*}{ NMinT } & MSE & 0.37 & 0.36 & 0.36 & 0.35 & 0.34 & 0.34 & 0.34 & 0.33 \\
\hline & AIC & 578.24 & 572.29 & 572.71 & 565.08 & 561.80 & 556.44 & 555.08 & 554.37 \\
\hline \multirow[t]{2}{*}{ NMaxT } & MSE & 0.39 & 0.39 & 0.39 & 0.39 & 0.39 & 0.39 & 0.39 & 0.39 \\
\hline & $\mathrm{AIC}$ & 596.95 & 594.27 & 595.89 & 597.59 & 597.90 & 599.53 & 601.53 & 602.61 \\
\hline \multirow[t]{2}{*}{$\mathrm{NRH}$} & MSE & 0.41 & 0.41 & 0.41 & 0.41 & 0.41 & 0.41 & 0.41 & 0.41 \\
\hline & $\mathrm{AIC}$ & 613.07 & 614.17 & 616.06 & 613.10 & 614.88 & 616.83 & 618.38 & 620.24 \\
\hline \multirow[t]{2}{*}{ NMinRH } & MSE & 0.38 & 0.41 & 0.41 & 0.41 & 0.41 & 0.41 & 0.41 & 0.41 \\
\hline & AIC & 584.97 & 584.97 & 616.12 & 614.50 & 615.81 & 617.67 & 618.55 & 620.07 \\
\hline \multirow[t]{2}{*}{ NMaxRH } & MSE & 0.41 & 0.41 & 0.41 & 0.41 & 0.41 & 0.41 & 0.41 & 0.42 \\
\hline & AIC & 612.86 & 614.68 & 616.68 & 617.28 & 619.21 & 619.06 & 621.01 & 623.00 \\
\hline \multirow[t]{2}{*}{ NRAIN } & MSE & 0.38 & 0.41 & 0.41 & 0.41 & 0.41 & 0.40 & 0.39 & 0.39 \\
\hline & AIC & 584.97 & 614.71 & 616.08 & 617.93 & 613.16 & 609.40 & 606.21 & 602.75 \\
\hline \multirow[t]{2}{*}{ NRAIND } & MSE & 0.41 & 0.41 & 0.41 & 0.41 & 0.40 & 0.39 & 0.38 & 0.36 \\
\hline & AIC & 612.94 & 614.92 & 616.84 & 618.49 & 610.47 & 603.19 & 592.83 & 581.51 \\
\hline \multirow[t]{2}{*}{ NT15RH90 } & MSE & 0.39 & 0.39 & 0.39 & 0.38 & 0.38 & 0.38 & 0.38 & 0.37 \\
\hline & AIC & 596.01 & 596.62 & 594.79 & 594.50 & 594.82 & 590.60 & 590.25 & 587.32 \\
\hline HDT20RH70 & MSE & 0.39 & 0.38 & 0.38 & 0.38 & 0.38 & 0.38 & 0.38 & 0.38 \\
\hline & $\mathrm{AIC}$ & 593.14 & 589.05 & 588.14 & 589.31 & 591.18 & 593.18 & 595.04 & 596.57 \\
\hline CHN-HDD & MSE & 0.36 & 0.33 & 0.28 & 0.13 & 0.11 & 0.12 & 0.12 & 0.12 \\
\hline & AIC & 570.03 & 542.51 & 499.52 & 248.67 & 217.25 & 219.24 & 221.24 & 222.73 \\
\hline
\end{tabular}

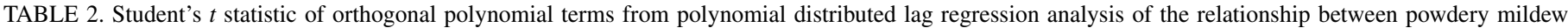

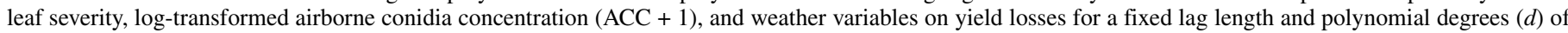
$0,1,2$, and 3

\begin{tabular}{|c|c|c|c|c|c|}
\hline \multirow[b]{2}{*}{ Variables $^{\mathrm{a}}$} & \multirow[b]{2}{*}{ Lag duration (n) } & \multicolumn{4}{|c|}{ Polynomial degree ${ }^{b}$} \\
\hline & & $d=0$ & $d=1$ & $d=2$ & $d=3$ \\
\hline PLAD & 4 & -5.24 & 11.80 & 3.75 & 0.89 \\
\hline $\log (A C C+1)$ & 3 & -2.82 & 13.64 & 0.35 & -0.63 \\
\hline HT25 & 7 & 5.88 & 4.57 & -1.53 & 0.32 \\
\hline $\mathrm{T}$ & 7 & -5.47 & 7.20 & 0.52 & 0.61 \\
\hline $\operatorname{MinT}$ & 7 & -5.80 & 8.54 & 1.31 & 0.38 \\
\hline HNT15 & 7 & 17.09 & -7.99 & -2.69 & 0.10 \\
\hline DMinT & 7 & -6.33 & 8.99 & 1.32 & 0.05 \\
\hline NMinT & 7 & -5.73 & 8.43 & 1.18 & -0.31 \\
\hline CHN-HDD & 4 & -9.57 & 20.27 & 4.46 & 0.78 \\
\hline
\end{tabular}

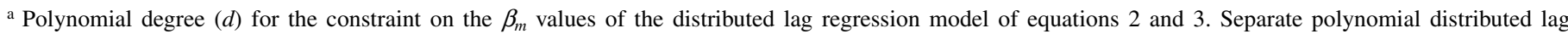
regression models with a fixed lag of $n$ were fitted to each weather variable using 386 observations collected in 2006, 2007, and 2008 at six strawberry fields. The highest-order term with the absolute value of $t>1.5$ was considered to be the appropriate polynomial degree.

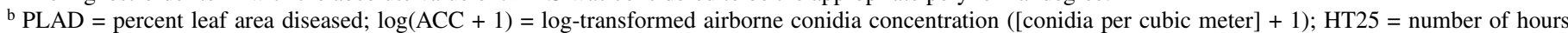
with temperature $\geq 25^{\circ} \mathrm{C}$; $\mathrm{T}=$ mean daily temperature $\left({ }^{\circ} \mathrm{C}\right)$; MinT $=$ minimum daily temperature $\left({ }^{\circ} \mathrm{C}\right)$; HNT15 $=$ number of hours during the night with temperature $\leq 15^{\circ} \mathrm{C}$; DMinT $=$ minimum day temperature $\left({ }^{\circ} \mathrm{C}\right)$; NMinT $=$ minimum night temperature $\left({ }^{\circ} \mathrm{C}\right)$; and $\mathrm{CHN}$-HDD $=$ daily number of hours of night temperature $\leq 15^{\circ} \mathrm{C}$ at relative humidity $(\mathrm{RH}) \geq 90 \%$ and day temperature $\geq 20^{\circ} \mathrm{C}$ at $\mathrm{RH} \leq 70 \%$. These variables were selected based on the mean square error and Akaike information criterion provided in Table 1 (smaller values).

ficient was 0.52 to 0.93 , with the coefficient of bias at 0.60 to 0.97 and $\mathrm{CCC}$ at 0.33 to 0.90 (Figs. $3 \mathrm{C}$ and $\mathrm{D}$ and $4 \mathrm{~F}$ to $\mathrm{J}$ ). The model containing only PLAD provided the best prediction of strawberry crop losses (Table 3; Fig. 3A and G). For the three data sets not used to construct the models (Fig. 1J and $\mathrm{K}$ ), plots of observed and predicted crop losses against day of the year clearly show that PLAD was a good crop loss indicator (Fig. 5). 


\section{DISCUSSION}

One of the foundations of long-lasting plant disease management strategies is the application of control measures only when the risk of disease represents a production cost higher than the expected losses in the absence of control measures (35). Therefore, the implementation of sustainable disease management systems requires precise information on the consequences of epidemics. The amount of crop loss that is acceptable depends on crop value, cost of control measures, and cost of harvesting, among other factors, and cannot be universally established. However, it is possible to establish the extent of crop losses and the factors that influence them. That was the main purpose of this study: to characterize strawberry crop losses caused by powdery mildew.

Determining the impact of plant diseases on yield or crop losses has long been critical in botanical epidemiology $(2,17,18,27)$, and there are several published models describing the relationship between disease incidence or severity and yield or losses with or without the inclusion of factors related to crop physiology $(15,18$, 27). In this study, we were interested in both describing the relationship between strawberry powdery mildew severity and crop losses and developing a model that could be used to predict crop losses so that control measures could be applied to prevent them. On day-neutral strawberry, the harvest period is not limited by a single flowering period because flowers are produced continuously until frost. Therefore, crop losses could be assessed numerous times and analyzed as a dynamic process with progressive and degressive phases. This characteristic offers the opportunity to predict losses and to act before the losses reach an economic threshold. In this study, we not only considered the dynamic of day-neutral strawberry crop losses but also the lag associations, with several weather- and monitoring-based variables making the

TABLE 3. Estimated parameters and corresponding standard errors (in parentheses) of 14 models (equation 4) describing the effects of composite monitoring- and weather-based variables on proportion of diseased berries

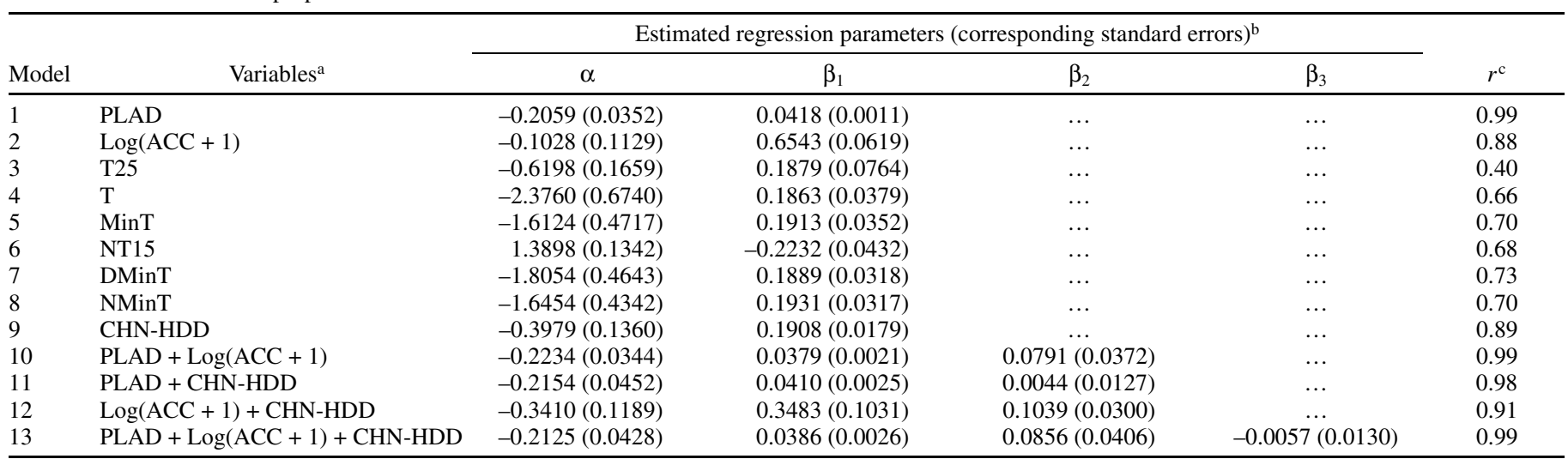

${ }^{a}$ Composites $\left(X^{*}\right.$; equation 8 ) of percent leaf area diseased (PLAD), log-transformed airborne conidia concentration [Log(ACC +1$)$ ], number of hours with temperature $\geq 25^{\circ} \mathrm{C}(\mathrm{T} 25)$, mean daily temperature (T), minimum daily temperature (MinT), number of hours during the night with temperature $\leq 15^{\circ} \mathrm{C}(\mathrm{HNT} 15)$, minimum day temperature (DMinT), minimum night temperature (NMinT), and daily number of hours of night temperature $\leq 15^{\circ} \mathrm{C}$ at relative humidity (RH) $\geq 90 \%$ and day temperature $\geq 20^{\circ} \mathrm{C}$ at $\mathrm{RH} \leq 70 \%$ (CHN-HDD). These variables were selected based on the mean square error and Akaike information criterion provided in Table 1 (smaller values). Weights for the constructions of the composite variables in equation 5 were based on the polynomial distributed lag regression analysis (equation 2).

${ }^{\mathrm{b}}$ Estimates of the marginal effects $\left(\beta^{*}\right)$ for composite monitoring- and weather-based-variables of equation 8.

${ }^{\mathrm{c}}$ Pearson product-moment correlation between observed and predicted yield losses.

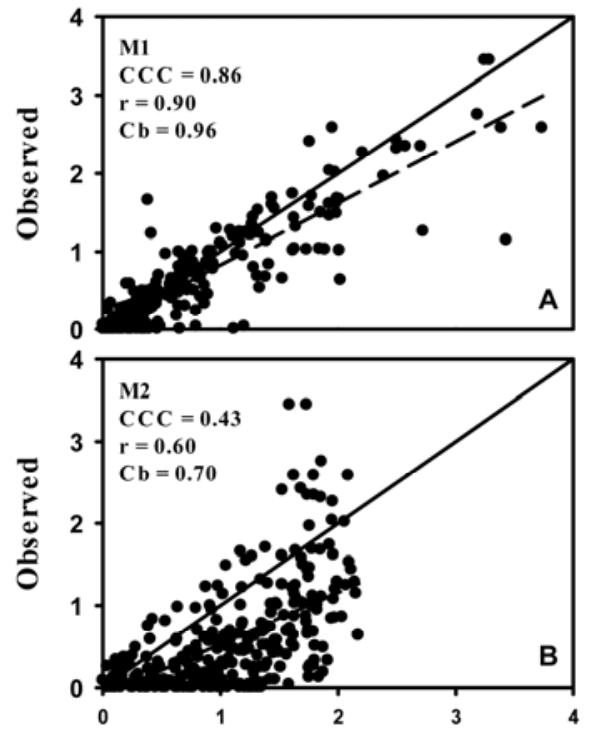

Predicted

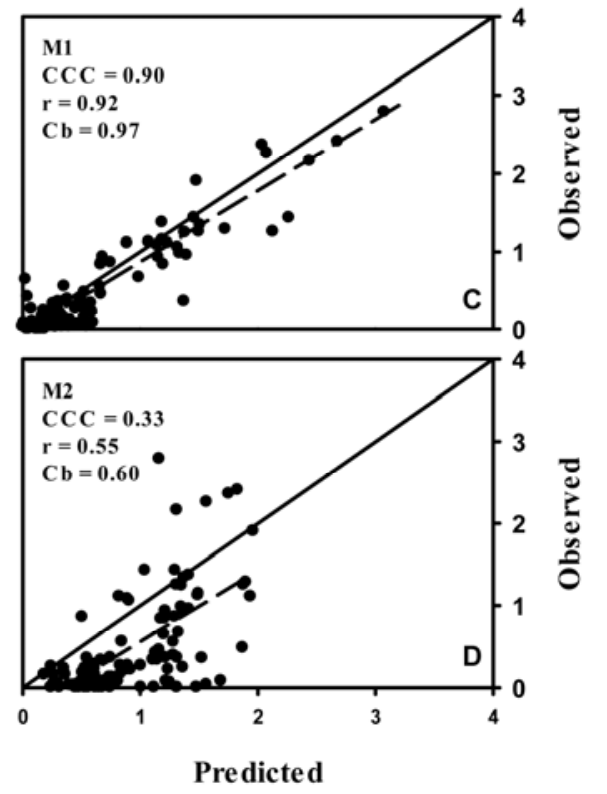

Predicted

Fig. 3. Relationship between observed and predicted strawberry crop losses caused by Podosphaera aphanis for two models developed using percent leaf area diseased (M1) and log-transformed airborne conidia concentration (M2) as composite variables (Table 3). Solid and broken lines represent the concordance and best fit lines, respectively. A and B, Observed values were used to build the models; C and D, observed values are independent data (not used to construct the models). $\mathrm{CCC}=$ concordance correlation coefficient and $C_{b}$ is a bias coefficient. 
analysis powerful. To our knowledge, it is the first time that such an approach was used to model crop losses.

In the 12 epidemics studied (in the day-neutral Seascape), crop losses varied from 9 to $30 \%$. These results are similar to those reported by Blanco et al. (4), who studied the relationship between $P$. aphanis airborne inoculum and the incidence of berries with powdery mildew, even though the comparison is difficult because losses were not measured in a comparable way. In the present study, there was a positive linear relationship between crop losses and the AUDPC $\left(R^{2}=0.90\right)$ and daily mean ACC $\left(R^{2}=0.86\right)$ and a negative linear relationship between losses and time to $5 \%$ loss $\left(R^{2}=0.76\right)$ and time to $5 \%$ leaf area diseased $\left(R^{2}=0.61\right)$. These
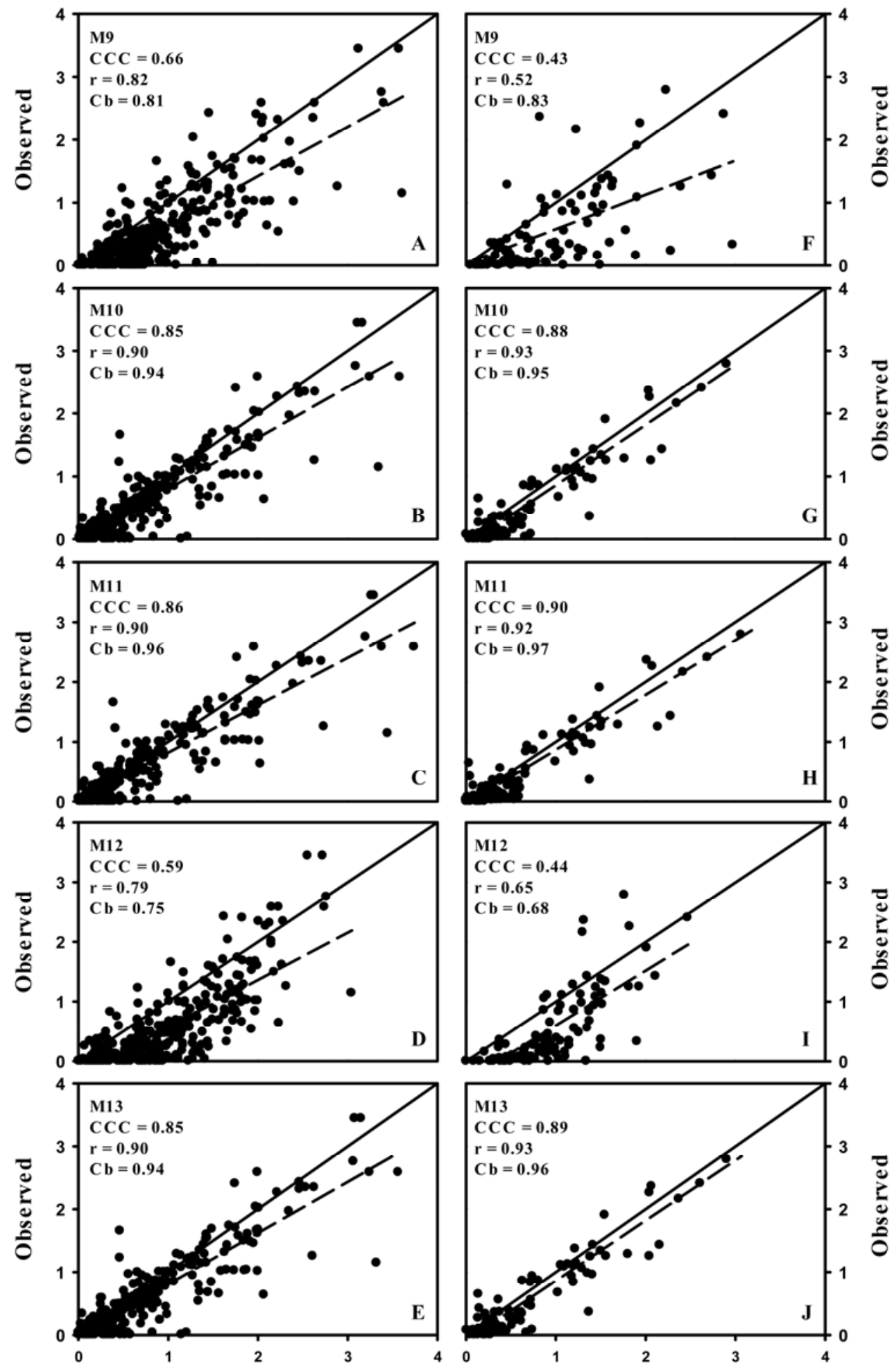

Predicted

Predicted

Fig. 4. Relationship between observed and predicted strawberry crop losses caused by Podosphaera aphanis for five models (M9, M10, M11, M12, and M13) containing different combinations of composite monitoring-based variables (percent leaf area diseased or $\log$ [airborne conidia concentration +1$]$ ) and the variable of a cold and humid night followed by a hot and dry day, which represents the daily number of hours of night temperature $\leq 15^{\circ} \mathrm{C}$ at relative humidity (RH) $\geq 90 \%$ and day temperature $\geq 20$ at $\mathrm{RH} \leq 70 \%$ (Table 3 ). Solid and broken lines represent the concordance and best fit lines, respectively. A to E, Observed values were used to build the models; $\mathbf{F}$ to $\mathbf{L}$, observed values are independent data (not used to construct the models). 
results suggest that both ACC and powdery mildew leaf severity are parameters that significantly influence berry losses.

The development of strawberry powdery mildew early-warning systems to predict when significant crop losses will occur was the motivation for this study. However, no consensus has emerged from the scientific literature on strawberry powdery mildew as to which weather factors should be used as indicators (1,19,31-33). In this study, a PDL model was used to evaluate the time lag distribution of the effects of percent leaf area diseased, airborne inoculum concentration, and several weather variables on crop losses on a June-bearing cultivar grown in open fields. This
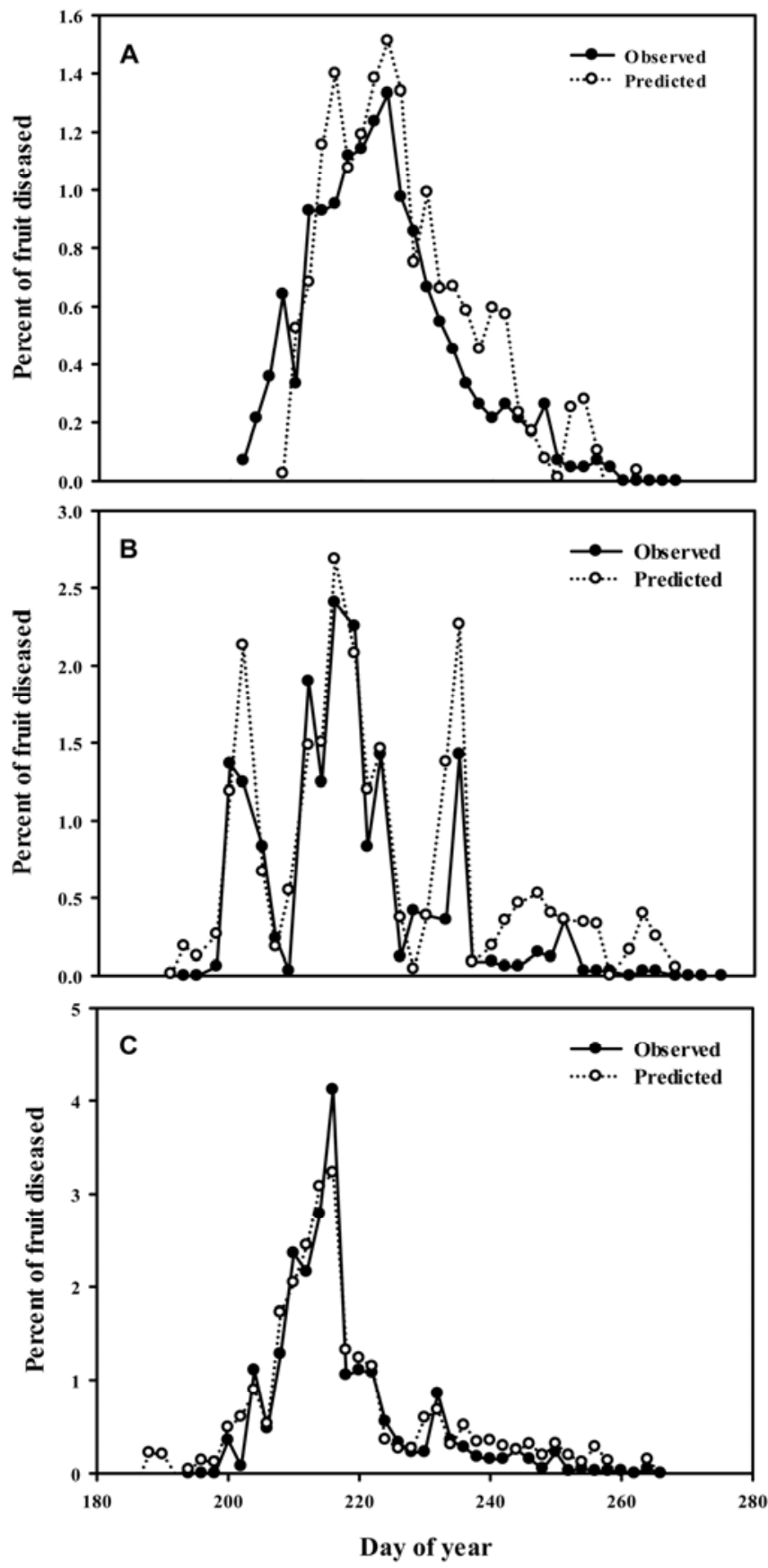

Fig. 5. Temporal progress of observed (filled circles) and predicted (empty circles) strawberry crop losses caused by Podosphaera aphanis at A, Frelighsburg in 2008; B, St. Paul-d'Abbotsford in 2007; and C, Ile d'Orléans in 2006. Predicted values were calculated as $Y=-0.2059+0.0418 \times X^{*}$, where, $X^{*}$ is a composite variable built from the percent leaf area diseased (PLAD) as $\mathrm{CPLAD}=(0.07086 \times \mathrm{PLAD})+\left(-0.1285 \times x_{1}\right)+\left(-0.0639 \times x_{2}\right)+0.264 \times$ $x_{3}+0.8570 \times x_{4}$, where the four $x$ variables are PLAD at lags of $1,2,3$, and 4 , respectively, with a polynomial degree of 2 (Table 2 ). modeling approach was chosen because it makes it possible to model the influence of several variables not only on the day of assessment but also on several days prior to assessment (21). In other words, polynomial lagged regression models could be used to model time series data in which the effects of the independent variables are distributed over time. In this study, it was assumed that the effect of the significant independent variables on crop losses was distributed over time; that is, a change in these variables at time $t$ will cause a change in berry losses at time $t$, and there will also be a delayed effect at times $t+1, t+2$, and so on up to time $t+n$. The inclusion of time lag distribution effects in the model gives it an intrinsic predictive ability. Among the 51 weather variables evaluated, only those related to temperature were associated with crop losses. However, none of the PDLREG models built with those weather variables provided accurate crop loss predictions, although the variable characterizing CHN-HDD was a good predictor of crop losses. A PDLREG model built using CHN-HDD with a time lag of 8 days and a polynomial degree of 2 provided a good description of the berry loss data used to construct the model ( $r=0.89$ and 0.82 ) but not of independent data $(r=0.52)$. Similarly, a PDLREG model built using ACC with a time lag of 6 days and a polynomial degree of 1 provided a good description of the berry loss data used to construct the model $(r=0.88$ and $0.60, \mathrm{CCC}=0.70)$ but was less accurate in describing independent data $(r=0.55)$. The best models were those that included PLAD but the incorporation of variables other than PLAD did not improve the accuracy of the models. The model built using PLAD with a time lag of 8 days and a polynomial degree of 2 provided a good description of the berry loss data used to construct the model $(r=0.99$ and 0.90$)$ and of independent data $(r=0.92)$. It is difficult to compare these findings with other scientific reports because very few studies have aimed to characterize strawberry crop losses due to powdery mildew $(4,7)$. However, the findings are consistent with the hypothesis that infected leaves serve as an inoculum source for berry infections. In several strawberry production areas, powdery mildew management mostly relies on the use of fungicides, which are used systematically over large areas (open fields production) or over long periods of time (large tunnel and greenhouse production) $(1,3,4,7,8,11,19,31)$. One way to improve this situation is to use a weather- or monitoring-based disease risk indicator. The model developed in this study can improve operational powdery mildew warnings. Based on percent leaf area diseased or on proportion of leaf diseased (8), the model can help decide whether to spray, not to spray, or wait, based on the grower's powdery mildew acceptance and expected economic benefits of the fungicide treatment. In this study, at the time when $5 \%$ crop loss was reached, an average of $17 \%$ leaf area diseased since the first leaf symptoms was observed. These key points should be considered in the development of an early-warning system for strawberry powdery mildew.

\section{ACKNOWLEDGMENTS}

This work was financially supported by Agriculture and Agri-Food Canada and the provincial funding programs Prime Vert and Conseil pour le Développement de l'Agriculture du Québec. The contribution of $\mathrm{H}$. Van der Heyden to this work was supported by Compagnie de recherche Phytodata Inc. We thank all the summer students and the scouts from the PRISME Consortium for their technical assistance, L. V. Madden for his advice on PDLREG analysis, and L. Willocquet and S. Savary for reviewing an early version of this manuscript.

\section{LITERATURE CITED}

1. Amsalem, L., Freeman, S., Rav-David, D., Nitzani, Y., Sztejnberg, A., Pertot, I., and Elad, Y. 2006. Effect of climatic factors on powdery mildew caused by Sphaerotheca macularis f. sp. fragariae on strawberry. Eur. J. Plant Pathol. 114:283-292. 
2. Bergamin Filho, A., Carneiro, S. M. T. P. G., Godoy, C. V., Amorim, L., Berger, R. D., and Hau, B. 1997. Angular leaf spot of Phaseolus beans: Relationships between disease, healthy leaf area, and yield. Phytopathology 87:506-515.

3. Berrie, A. M., and Burgess, C. M. 1997. The effect of post-harvest epidemics of powdery mildew on yield and growth of strawberry cv. Elsanta. Proc. Third Strawberry Symp. Acta Hortic. 439:791-798.

4. Blanco, C., de los Santos, B., Barrau, C., Arroyo, F. T., Porras, M., and Romero, F. 2004. Relationship among concentrations of Sphaerotheca macularis conidia in the air, environmental conditions, and the incidence of powdery mildew in strawberry. Plant Dis. 88:878-881.

5. Braga, A. L. F., Zanobetti, A., and Schwartz, J. 2001. The time course of weather-related deaths. Epidemiology 12:662-667.

6. Calonnec, A., Cartolaro, P., and Chadoeuf, J. 2009. Highlighting features of spatiotemporal spread of powdery mildew epidemics in the vineyard using statistical modeling on field experimental data. Phytopathology 99:411-422.

7. Carisse, O., and Bouchard, J. 2010. Age-related susceptibility of strawberry leaves and berries to infection by Podosphaera aphanis. Crop Prot. 29:969-978.

8. Carisse, O., Lefebvre, A., Van der Heyden, H., Roberge, L., and Brodeur, L. 2013. Analysis of incidence-severity relationships for strawberry powdery mildew as influenced by cultivar, cultivar type, and production systems. Plant Dis. 97:354-362.

9. Corke, A. T. K., and Jordan, V. W. L. 1978. Powdery mildews of bush and soft fruits. Pages 347-358 in: The Powdery Mildews. D. M. Spencer, ed. Academic Press, New York.

10. Dent, J. B., and Blackie, M. J. 1979. Systems Simulation in Agriculture. Applied Science Publishers Ltd., London.

11. Freeman, J. A., and Pepin, H. S. 1969. Effect of postharvest infection of powdery mildew on yield of the strawberry cultivar Northwest. Can. Plant Dis. Surv. 49:139.

12. Gooding, H. J., McNicol, R. J., and MacIntyre, D. 1981. Methods of screening strawberries for resistance to Sphaerotheca macularis (Wall ex Frier) and Phytophthora cactorum (Leb. and Cohn). J. Hortic. Sci. 56:239-246.

13. Holb, I. J., Heijne, B., Withagen, J. C. M., Gáll, J. M., and Jeger, M. J. 2005. Analysis of summer epidemic progress of apple scab at different apple production systems in the Netherlands and Hungary. Phytopathology 95:1001-1020.

14. Jhooty, J. S., and McKeen, W. E. 1965. Studies on powdery mildew of strawberry caused by Sphaerotheca macularis. Phytopathology 55:281285.

15. Johnson, K. B. 1987. Defoliation, disease, and growth: A reply. Phytopathology 77:1495-1497.

16. Maas, J. L., Ed. 1998. Compendium of Strawberry Diseases, 2nd ed. American Phytopathological Society Press, St. Paul, MN.

17. Madden, L. V., Hughes, G., and van den Bosch, F. 2007. The Study of Plant Disease Epidemics. American Phytopathological Society, St. Paul, MN.

18. Madden, L. V., and Nutter Jr., F. W. 1995. Modeling crop losses at the field scale. Can. J. Plant Pathol. 17:124-137.
19. Miller, T. C., Gubler, W. D., Geng, S., and Rizzo, D. M. 2003. Effects of temperature and water vapor pressure on conidial germination and lesion expansion of Sphaerotheca macularis f. sp. fragariae. Plant Dis. 87:484492.

20. Mukerji, K. G. 1968. Sphaerotheca macularis. C.M.I. Descriptions of Pathogenic Fungi and Bacteria, No. 188. Commonwealth Mycological Institute, Kew, UK.

21. Paul, P. A., Lipps, P. E., De Wolf, E., Shaner, G., Buechley, G., Adhikari, T., Ali, S., Stein, J., Osborne, L., and Madden, L. V. 2007. A distributed lag analysis of the relationship between Gibberella zeae inoculum density on wheat spikes and weather variables. Phytopathology 97:1608-1624.

22. Peries, O. S. 1962. Studies on strawberry mildew, caused by Sphaerotheca macularis (Wallr. ex Fries) Jaczewski: I. Biology of the fungus. Ann. Appl. Biol. 50:211-224.

23. Peries, O. S. 1962. Studies on strawberry mildew, caused by Sphaerotheca macularis (Wallr. ex Fries) Jaczewski: II. Host-parasite relationships on foliage of strawberry varieties. Ann. Appl. Biol. 50:225-233.

24. Rossi, V., Caffi, T., Giosuè, S., and Bugiani, R. 2008. A mechanist model simulating primary infections of downy mildew in grapevine. Ecol. Model. 212:480-491.

25. SAS Institute, Inc. 2010. SAS/ETS 9.22 User's Guide. SAS Institute Inc., Cary, NC.

26. Savary, S., Delbac, L., Rochas, A., Taisant, G., and Willocquet, L. 2009. Analysis of nonlinear relationships in dual epidemics, and its application to the management of grapevine downy and powdery mildews. Phytopathology 99:930-942.

27. Savary, S, Teng, P. S., Willocquet, L., and Nutter, F. W., Jr. 2006. Quantification and modeling of crop losses: A review of purposes. Annu. Rev. Phytopathol. 44:89-112.

28. Schabenberger, O., and Pierce, F. J. 2002. Contemporary Statistical Models for the Plant and Soil Sciences. CRC Press, New York.

29. Schwartz, J. 2000. The distributed lag between air pollution and daily deaths. Epidemiology 11:320-326.

30. Sivapalan, A. 1993. Effect of water on germination of powdery mildew conidia. Mycol. Res. 97:71-76.

31. Sombardier, A., Savary, S., Blancard, D., Jolivet, J., and Willocquet, L. 2009. Effects of leaf surface and temperature on monocyclic processes in Podosphaera aphanis, causing powdery mildew of strawberry. Can. J. Plant Pathol. 31:439-448.

32. Van der Heyden, H., Lefebvre, M., Roberge, L., Brodeur, L., and Carisse, O. Spatial pattern of strawberry powdery mildew (Podosphaera aphanis) severity and airborne inoculum. Plant Dis. In press.

33. Willocquet, L., Sombardier, A., Blancard, D., Jolivet, J., and Savary, S. 2008. Spore dispersal and disease gradients in strawberry powdery mildew. Can. J. Plant Pathol. 30:434-441.

34. Xiao, C. L., Chandler, C. K., Price, J. F., Duval, J. R., Mertely, J. C., and Legard, D. E., 2001. Comparison of epidemics of Botrytis fruit rot and powdery mildew of strawberry in large plastic tunnel and field production systems. Plant Dis. 85, 901-909.

35. Zadoks, J. C. 1985. On the conceptual basis of crop loss assessment: The threshold theory. Annu. Rev. Phytopathol. 23:455-473.

\section{Erratum}

Equations 1, 2, 7, and 8 were corrected in this article. In addition, in the paragraph following equation 8, GLM was changed to GLIMMIX. Changes to this article were made on August 16, 2013. 